\title{
Expanded Participant Network: Digital Fan Activism Transformed into the Economic and Political Sphere in China
}

\author{
Shuang $\mathrm{Zhao}^{1,{ }^{*}}$ Chenyu $\mathrm{Ni}^{1}$ \\ ${ }^{1}$ Department of Digital Humanities, King's College London, London, UK \\ *Corresponding author. Email: wzhaoshuang2018@sina.com
}

\begin{abstract}
Fan activism is getting attention from scholars as its influence is gradually spreading into the economic sphere, even political space. During the outbreak of COVID-19, a movement around actor Xiao Zhan became the hottest issue on Weibo. Rather than just discussing how fanatic those fans were, people had conversations around economy and politics, such as the resistance to capital, the reputation rights of celebrities and the use of civil rights. To illustrate how Xiao Zhan movement was transformed from fandom to the economic and political sphere, this study applied Jenkin's views of participatory culture while also considering the digital surveillance and censorship in China. With participant observation and interviews, this study sorted out some details of the development process of the movement. Finally, it found that fans, media, businesses and even the state were all embroiled in a network as participants. They expanded the participant network while interacting with each other.
\end{abstract}

\section{Keywords: fan activism, participatory culture, digital surveillance and censorship}

\section{INTRODUCTION}

With the expansion of massive cultural production and advancing online space, Chinese online fan community has grown rapidly in recent years (Zhang and Mao, 2013, p.45). Meanwhile, activism within these fan communities has been gradually exposed to the public and some even caused economic and political consequences. From February 27, Conversations around Xiao Zhan movement continues to heat up, culminating in a series of digital protests on Weibo. The movement even spread to twitter and sparked lots of conversion under the trend of \#WeLoveXIoaZhan\#. At the beginning, some fans on Weibo claimed that a fan fiction insulted their idols as it described Xiao as a sex worker. These activists soon reported the fanfiction and Archive of Our Own (AO3), the platform on which this fiction published, to the authorities on suspicion of pornography. These collective actions drew criticism from other fan groups. Conversions reached a climax after authorities banned $\mathrm{AO} 3$ and evolved into a hot issue with economic and political implications.

Xiao Zhan is famous for staring TV series Chen Qing Ling, an intellectual property owned by Tencent. The birth of its derivative works has witnessed the circulation of media content in the context of participatory culture and gives an insight into the complex partnership between fans, media consumers, corporations and the government. To paraphrase what
Jenkins mentioned in Convergence Culture, they are participants "who interact with each other according to a new set of rules that none of us fully understands." (Jenkins, 2006a, p.3). In this case, these interactions first happened between fans and corporate media, and the power of this partnership allowed Xiao Zhan movement to expand into the entertainment system. The partnership between fans and government authorities was formed when fans of Xiao used 'reporting', one of the civil rights in China. The complex network of all the participants transferred the movement into social conversions about reporting as a civil right, creative freedom and even LGBT rights. A similar pattern can be found in Chinese translation communities. Their online activities changed from pleasure-seeking to educational and social values, such as public courses offered by world-renowned universities (Zhang and Mao, 2013). However, in Xiao Zhan movement, fans lost some of their initiatives when the conversation was shifted from fandom to public space. "Not all participants are created equal" (Jenkins, 2006a, p.3). Both the fans and anti were more or less limited by other participants with greater power.

Henry Jenkins saw participatory culture can be transferable from cultural consumption to political engagement and laid out the ways in which fans start political activism. A gap here is how the complex network of participants affects this transformation process. Did the strict online censorship block the 
process? How did the interaction between corporate media and media consumers affect this process? Drawing on these two sub-questions, this study tried to answer how did fan activism on Chinese social media evolved into political activism in the context of Xiao Zhan movement. With the application of participatory observation and interview research methods, this study firstly found that the interactions between corporate media with fans or anti compounded the economic impact of Xiao Zhan movement. In addition, reporting as a way of censorship can react as direct interactions between fans and government authorities, and it accelerated the movement's entry into the political sphere.

\section{PARTicipatory CUlTuRe, COllective INTELLIGENCE AND FAN ACTIVISM}

Discussions about participatory culture are mentioned early in Jenkin's book, Textual Poacher in 1992. Along with the phrase "convergence, the concept "participatory culture' was developed further in Convergence Culture (Ihlebaek, 2017). In this book, Jenkins (2006a, p.3) noted that "participatory culture contrasts with older notions of passive media spectatorship". Additionally, Jenkins went deeper into the fandom of Star Wars and Harry Potter to explain how fans reshaped the media content to satisfy their own fantasies and how the corporate media tried to find the balance between encouraging fan participation and protecting their interests (ibid). In Jenkins later book Participatory Culture in a Networked Era, Jenkins, Ito and boyd noted that participatory culture points to "both descriptive and aspirational dimensions" (Ihlebaek, 2017). While descriptive dimension means the process of carrying out participatory practices and forms of cultural production, the other focuses on how these practices motivate and empower different groups (ibid). Moreover, the authors thought about both the positive and negative sides of the development of participatory culture (ibid). The positive side was discussed within a wide range of fields scholarly. Leon, Correa, Aramberri and de Aberasturi (2011) examined how the practice of social participation benefits literacy work in the Museos Vivos project. He noted that compared with developing individual skills, group learning and interactions work better for citizens to acquire the skills (ibid). Discussions around the negative side are mostly related to the commercialisation of participation.

Another key term in Jenkin's Convergence Culture is collective intelligence. Jenkins related collective intelligence with fan practices, such as spoiling, and saw it as the "ability of virtual communities to leverage the combined expertise of their members" (2006a, p.27). Knowledge communities were mentioned here to describe the organizations which allow media consumers to have greater leverage in negotiations with media producers (ibid). To illustrate how collective practices work in knowledge communities, Jenkins investigated survivor spoilers about how they became spoilers and started spoiling. Collective intelligence was key to the daily practices of Chinese translation communities. Zhang and Mao (2013) explored the way Chinese translation communities approached into producing political contents. During the translation of entertainment content, participatory civic culture is likely to emerge from the collaboration practices (ibid).

With the notion of participatory culture and collective intelligence, fan activism gets more attention. Its concept evolved with the three waves of fan studies. Rowe saw fan activism as grass-roots resistance to cultural capitalism (Rowe, Ruddock and Hutchins, 2010). For instance, the fans of The Last Airbender challenged Paramount's casting decisions as the corporate media cast four white men in Asian roles (Lopez, 2011). Their feverish involvement in fictional texts was translated into a series of organized politicization (ibid). However, when these fans' resistance was way beyond the text of The Last Airbender, they were still consumers who wanted to spend their money on their favourite text (ibid). Their collective goal was to influence the film industry through their boycott (ibid). In this way, they sent a message about how important racial politics were to them as consumer-citizens (ibid). Many scholars saw the potential for fan activism to transform into political influential movement. Jenkins (2006b) examined how fan activists step out of fandom and start to affect politics. Those consumer-citizens apply what they poached from media to politicization (ibid). Like what Lopez (2011) found in the protests for The Last Airbender, fans poached "racebending" from the media content and used it to set up the website on which they organized protests and announced movements.

A gap here is that how does fan activism that is not intended to reach a political goal enter into political discourse passively. In many cases, the goal of fan activism was neither resistance to cultural capitalism nor pursuit of politicization. As more participants take part, the power of fan activism was inserted into political discourse. Compared with fan practices, participants network has rarely been discussed in the research of fan activism. However, they are very critical to help understand the interactions under the chaos and figure out what is driving the process of politicization.

\section{DIGITAL SURVEILLANCE AND CENSORSHIP IN CHINA}

In the early days of the Internet, some scholars saw the internet as a tool which can strengthen a new civil society in which individuals are empowered, independent mobilization and communication are facilitated (Diamond, 2010 cited in Chang and Lin, 
2020). However, state surveillance and censorship are never far from the digital worlds. A variety of new technologies have been adopted by governments to mitigate the threat, including blocking, hacking, targeted surveillance, as well as social malware (Chang and Lin, 2020). Both authoritarian and democratic governments have used internet censorship for national security (ibid). Restricting the flow of information over the Internet is the first strategy for governments to gain control (ibid). Apart from that, the authoritarian regime also uses complex internet censorship for consolidate political power (ibid).

In Western media reportage of China, Internet censorship is a recurring topic (Yang, 2016). Meanwhile, research on online surveillance and censorship is growing (ibid). As the largest authoritarian regime in the world, China has a complex operation of online censorship, and this causes that most internet users in China seem to prefer using Internet as entertainment rather than politics (ibid). However, the fear of censorship remains within the realm of entertainment. Solf entertainment and popular culture still "serve a conservative role of social pacification" and "function to sustain the party's continuing political dominance" (Zhao, 2008, p.233). Therefore, Yang (2016) argued that the effects of China's Internet surveillance and censorship are in the realm of meaning-making. For instance, the party-state continues to selectively collaborate transnational and domestic private capital in some media and communication sectors (Zhang and Mao, 2013). In this way, the state still keeps ideological control when the media and cultural markets response to popular tastes (ibid).

Because of the connections between the state capital and private capital in the media and communication sectors, non-state media corporate is also involved in strengthening censorship. The principle of "selfdiscipline" is adopted by service providers to make sure market exposure (Yang, 2016). The capacity of the online discussion space is quite detrimental due to the risk of openly antagonizing views (Zhang and Mao, 2013). Thus, the online space in China has become a marketplace that encourages sensational performance and voyeurism (ibid). Fans and fandom in China fully embody the characteristics of China's cyberspace. For instance, there was a kind of "algorithms culture" which required fans to routinize data labour in their everyday practices of Weibo and learn algorithmic rules to satisfy their requirements as Weibo users or fans (Yin, 2020). This pattern was shaped by the platform's algorithms, or in other words, controlled by the technological affordances of the media corporate (ibid). Compared with private capital, Chinese state capital seems to have few involvements in fandom. The government has a fairly tolerant attitude towards fans and fandom, as long as their daily activities are kept within the level of material consumption and the party's discipline (Zhang and Mao, 2013).

Nevertheless, fandom is not always safe from politics. On large social platforms as Weibo, there is a special surveillance system which is rarely mentioned in related research. It can be interpreted as "reporting". Like the slogan "see it, say it, sorted" on London underground and "Whistleblowing" in American slang, the special surveillance system allows people to report to the authorities when they see something that doesn't look right. As a kind of service supported by technology, "reporting" has rarely been discussed in studies trying to figure out how do fans' political engagements start in China. This gap will be filled in this study.

\section{METHOD}

This research design was carried out based on the case study of Xiao Zhan movement. Hancke (2009) pointed out that the case stands out from many cases owing to its unique value, which is reflected in the interest and interpretation of researchers. Xiao Zhan movement happened during the outbreak of COVID-19. Surrounded by information about the worldwide epidemic, the movement still got considerable attention and public discussions. Additionally, compared with other fan protests, it has greater political and economic implications and thus helps us to figure out the relationship between fans, media corporate and related state departments in the network of participants.

Firstly, this study also used online participant observation to gather information for Xiao Zhan movement from the beginning to the present. Participant observation is a common data collection method for the study of fan activism. The movement went viral on Weibo, which can be viewed as a semipublic setting. This study used gatekeeping rules to get access. Two key informants were chosen to help record the details in the movement. One of them recognized herself as a fan of Xiao, the other belongs to another fan community and named herself as anti of Xiao. This gave a more comprehensive impression of the movement.

Additionally, this study used a semi-structured interview to collect data from individual fans to answer the two sub-questions. Compared to the guided interview, the semi-structured interview focuses more on participants' responses (McIntosh and Morse, 2015). This characteristic is very helpful to illustrate the whole picture of the movement from the fans' perspectives. This study chose descriptive/interpretive SSI to privilege the fans' experience. In particular, the author posted the recruitment of online surveys, which takes five minutes at most for participants to complete. This pre-survey aimed to gather basic information (e.g., age, occupation). After the pre-survey, the selected six 
participants who were more experienced in the movement were engaged in a 20 -minute interview. All the participants were young female between the age of 20-25 who claims to have no special identity other than members of fan communities. Three defines themselves as fans of Xiao, while the other three consider themselves as anti the semi-structure interview included nine questions which were designed around two subquestions.

\section{THE COMMERCIALIZATION OF FAN PARTICIPANTS AND AN EXPANDED PARTICIPANT NETWORK}

The TV series Chen Qing Ling is a product of the commercialization of the participants. The media corporate Tencent established a close relationship with media consumers by encouraging the reshape of media content. To be specific, fans were encouraged to romanticize the relationship between the two protagonists (Wei and Lan) and ship the corresponding real-person couple (Xiao and Wang). Fans poached media contents that show the interactions between the two actors through a variety of channels, and draw their own romantic stories from these materials. This poaching action shared a similar nature with spoiling, and that is collective intelligence. As a result, a large number of fan works were produced, in the form of fictions, videos and pictures,. While fans used media contents to satisfy their own fantasies, the corporate media was also using their fan works to commercialize this participatory practice. Tong, A shipper of Xiao and Wang, noticed this,

"I found that a video clip received an unusually high level of attention, but soon I found this was because of money. The video clip was made by a fan I follow, and the main content was her reaction to the trivia of the TV series. I think the company spent money to make the video go viral."

The company she mentioned refers to Tencent, which owns the intellectual property and the social platform Weibo. When fans were poaching and reshaping the contents, their works were also poached by Weibo and became a tool to gain attention and bring effects. Apart from that, fans daily practices on Weibo were guided by the algorithmic rules of the platform. The affective labour was poured into virtual data which can prove their idol's reputation. When Chen Qing Lin was airing, Xiao and Wang got a high ranking in a variety of lists that show the popularity of celebrities on Weibo. The corporate media made fans data workers through the algorithmic rules of Weibo to complete the commercialization of fan participation.

While the commercialization made Chen Qing Ling one of the most popular TV series and Xiao one of the hottest new actor, it also accelerated the spread of Xiao
Zhan movement throughout the network. anti who lost AO3 explored the capital participation behind the popularity, seeing it as a breach of market rules and a deprivation of consumer rights. Accordingly, the boycott against Xiao and his fans turned into against the capital behind him. For instance, Olay, a cosmetics brand endorsed by Xiao, was boycotted by anti after the manager expressed support for Xiao in a live stream. An anti fan Yue started to ask Olay for the invoice after she learned how to do it from other anti.

"I'm involved in invoicing, which is basically the same as forcing Olay to pay taxes. First, I checked to see if there were any orders from Olay on Taobao, as the invoice could be issued below. In the beginning, the customer service did not give me paper invoices but asked me to issue an electronic invoice. After repeated requests from hundreds of people, Olay opened a link to obtain paper invoices. Then I got two invoices."

Apart from Olay, FILA and Esquire were attacked by anti and suffered a public relations crisis. The collective intelligence here drove the anti to explore the negative news about these brands and make it visible for consumers and the state. FILA was accused of cheating and selling goods at high prices to domestic consumers, while Esquire was warned about the wrong political stance. Moreover, anti also supported competitors to those brands. In order to make the resistance more effective, they even developed the tactics. One of the most interesting strategies was based on the algorithm rules of Alibaba: searching for cosmetics without typing the brand name on Taobao and then click the corresponding products but do not buy it. This could generate advertising costs for the brand as the conversion rate was decreased.

There was a complex partnership between fans, and corporate media allowed the economic impact of the protest to grow. As Fang said, "We didn't start the boycott directly, but hope people can stop buying products related to Xiao. However, Olay's support for Xiao made us aggressive." For some anti, Xiao, fans of Xiao and the capital behind were tied together. The infiltration of capital into the fandom broke their rules. Therefore, anti went from boycotting Xiao to a variety of brands, Weibo and Tencent. While anti saw the corporate media as the enemy, fans of Xiao were trying to help maintain the partnership with Tencent. Whether for maintenance or resistance, the penetration of capital made the boundaries of participants network wider and allowed the movement to influence other spheres.

\section{THE USE OF REPORTING AND THE POLITICIZATION OF DISPUTE IN FANDOM}

Most fans and anti saw reporting as the trigger of all the protests but focused on different perspectives. Yue thought this problem from her perspective, "If there was 
not reporting, they wouldn't be able to do it." However, it is not clear whether AO3 is banned due to fans' reporting. Another view was that AO3 was banned in relation to the state's special campaign to 'clean up' the network environment. Those who hold this view argued that the power of fans could not influence the state's policy. Regardless of whether the trigger to ban AO3 was reporting or not, the movement became a political event through the participant network.

There was another expansion of the participant network when fans and anti were both reporting on the grounds of civil rights. The prohibition of AO3 made anti want an "eye for eye, tooth for tooth" revenge, and thus some of them reported Xiao and his fans to state authorities. Starting from fandom, reporting spread to the entertainment industry and soon others. Fans had a relatively limited range of targets - anti and the platform on which they launched campaigns. In contrast, anti contributed to the expansion of the participant network as they set their sights on the capital behind Xiao. They reported those variety shows in which Xiao was invited and the brands he endorsed. Fang learned from her peers' resistance tactics, "Food, cosmetics. We even found that some brands violated the law of advertising, and they were investigated by corresponding authorities because of our reporting". Fang had never been involved in any kind of fan activism before, but this time she took the initiative to contact corporation and authorities. Like Fang, many anti were not activists but forced to be a participant due to reporting. According to Fang, fans reported her most frequently used live streaming platform to the state authority because a podcast criticized Xiao. Meanwhile, fans were continued their reporting as the anti resistance continued, and the influence had a growing tendency. The nature of reporting transformed from a right of supervision to a tool of fighting, drawing more people into the network of participants.

The expanding participant network helped Xiao Zhan movement to move from fandom to politics. With the strict censorship and supervision in China, the state actually did not encourage too much discussion of politics online. Fans are especially marginalized and rarely mentioned in the mainstream media. Moreover, most fan communities have their own rules, agreeing not to touch-sensitive issues beyond the boundaries. Reporting is a sensitive behaviour in fandom cause once this happens, it will no longer be a simple matter of disputes in fandom. As imagine, whistleblowing indeed leaded to the participation of the state. Media serving the party commented on this incident from different perspectives. Some questioned about the boundaries of fan work, while others focused on whether the behaviour of fans was justified. The Procuratorial Daily was one of the media that mentioned about whether reporting should be done. With the expansion of the network, there was a wider variety of political topics being discussed in the media. Some were around regulating the digital environment, the protection of the rights of celebrities and even the mess of the entertainment industry.

\section{CONCLUSION}

Xiao Zhan Movement was more than just a battle between fans and anti by the late stage. It should be the resistance of media consumers to the private capital, and a political discussion based on the use of the civil right. As a product of participatory culture, Chen Qing Ling was a successful example of commercialization of fan participant. It was born out of a network in which fans and corporate media were closely related. This is a potential trigger of the movement and gave anti the best reason to boycott every brand who stand behind Xiao in the name of consumers. With the efforts of fans and anti, the participant network expanded into entertainment and consumer goods. The interactions between them and the brands actually made connections like two nodes in the network. With the interactions of nodes, the influence of the movement also grew rapidly.

The special digital surveillance in China helped make this movement a political issue, though sensitive discussions were not encouraged under this system. Reporting was a direct way to contact with the state, and thus it became an untouchable line for fans. However, this rule was broken at first when fans of Xiao were dissatisfied with the description of Xiao in a fanfiction. An "eye for eye, tooth for tooth" revenge was taken by anti who lost AO3. Accordingly, more reporting happened to different domains. A debate had been raging in cyberspace about whether reporting was a legitimate civil right. Newspapers working for the state became the nodes in the participant network. While they were spreading their views, they accelerated the transformation process in the nature of reporting.

This paper examined how fan activism was transformed into a political issue. The result found that there was an expansion of the participant network due to the commercialization of fan participants and the use of reporting as a civil right. One drawback was that the research subjects were all fans. As parts of the participant network, staffs in corporations and state were also important to help to see the whole participant network. In future research, this problem will be solved, and a more accurate map of the network should be designed accordingly.

\section{References}

[1] Zhang, W.-Y. and Mao, C.-T. 2013. Fan activism sustained and challenged: participatory culture in Chinese online translation communities. Chinese Journal of Communication, 6 (1), pp.4561 . 
[2] Jenkins, H. 2006. Convergence Culture: Where Old and New Media Collide. New York: NYU press.

[3] Ihlebaek, K.A. 2017. Participatory Culture in a Networked Era. Information, Communication and Society. doi: 10.1080/1369118X.2017.1417462. (accessed on May 20 2020)

[4] León, M.S., Correa, J.M., Aramberri, J.M., and de Aberasturi, E.J. 2011. An analysis of how the participatory culture through the Internet is fostered in policies directed towards non-formal educational contexts. Social and Behavioral Sciences, 28, pp.259-261.

[5] Rowe D., Ruddock, A. and Hutchins, B. 2010. Cultures of Complaint: Online Fan Message Boards and Networked Digital Media Sport Communities. Convergence: The International Journal of Research into New Media Technologies, 16 (3), pp.298-315.

[6] Lopez, L.K. 2011. Fan Activists and the Politics of Race in The Last Airbender. International Journal of Cultural Studies. 15 (5), pp.431-445.

[7] Jenkins, H. 2006. Fans, bloggers, and gamers: Exploring participatory culture. New York: NYU press,

[8] Chang, C.-C. and Lin, T.-H. 2020. Autocracy Login: Internet Censorship and Civil Society in the Digital Age. Democratization, 27 (5), pp.874-895.

[9] Yang, F. 2016. Rethinking China's Internet Censorship: The Practice of Recording and the politics of visibility. New Media and Society, 18 (7), pp.1364-1381.

[10] Zhao, Y.-Z. 2008. Communication in China: Political Economy, Power, and Conflict. Lanham: Rowman \& Littlefield,

[11] Yin, Y. 2020. An emergent algorithmic culture: The data-ization of online fandom in China. International Journal of Cultural Studies, 00 (0), pp.1-18.

[12] Hancké, B. 2013. Intelligent research design. Oxford: Oxford University Press, pp.60-83.

[13] McIntosh, M.J. and Morse, J.M. 2015. Situating and Constructing Diversity in Semi-Structured Interviews. Global Qualitative Nursing Research. doi: $10.1177 / 2333393615597674$. 